\title{
Прецизионное химическое травление эпитаксиальных слоев GaP(NAs) для формирования монолитных оптоэлектронных приборов
}

\author{
(С) Д.А. Кудряшов ${ }^{1}$, А.С. Гудовских ${ }^{1,2}$, А.И. Баранов ${ }^{1}$ \\ ${ }^{1}$ Санкт-Петербургский национальный исследовательский Академический университет \\ Российской академии наук, \\ 194021 Санкт-Петербург, Россия \\ ${ }^{2}$ Санкт-Петербургский государственный электротехнический университет „ЛЭТИ“ им. В.И. Ульянова (Ленина), \\ 197376 Санкт-Петербург, Россия \\ E-mail: kudryashovda@spbau.ru
}

(Получена 18 июня 2018 г. Принята к печати 2 июля 2018 г.)

\begin{abstract}
Приводятся результаты исследования применимости различных травителей для целей прецизионного жидкостного травления структур монолитных оптоэлектронных приборов, содержащих слои GaPNAs. Было показано, что травитель на основе иодада калия и соляной кислоты наилучшим образом подходит для данной задачи. Наличие в составе полупроводника азота (до 4\%) и мышьяка не оказывает существенного влияния на работу травителя, однако требует проведения дополнительных калибровочных экспериментов по уточнению скорости травления в каждом конкретном случае. В работе представлены примеры практического применения прецизионного травления для измерения характеристик солнечных элементов на основе GaPNAs.
\end{abstract}

DOI: 10.21883/FTP.2018.13.46885.8937

\section{1. Введение}

В настоящее время кремний является доминирующим полупроводниковым материалом электроники и микроэлектронной интегральной схемотехники, а также солнечной энергетики. Развитие уровня интеграции и скорости передачи информации для современных интегральных схем требует более существенной степени компоновки узлов приема-передачи оптического излучения и обработки данных. В связи с этим реализация монолитных оптоэлектронных микросхем на основе кремния кардинально увеличит функциональность кремниевой микроэлектроники и откроет совершенно новые области ее применения, а потенциальные преимущества монолитных многопереходных солнечных элементов на основе кремния заключаются в возможности существенно повысить их кпд, сохраняя относительно низкую стоимость. Для создания монолитных оптоэлектронных приборов на основе $\mathrm{Si}$ необходима разработка технологии синтеза прямозонных полупроводниковых материалов на подложках кремния, а также технологии постростового процессирования излучающих и фотопреобразующих структур.

В последнее время среди исследователей растет интерес к фосфиду галлия и его химическим соединениям с азотом и мышьяком [1-3]. Данный материал имеет близкую к кремнию постоянную решетки, что дает потенциальную возможность формировать качественные эпитаксиальные слои на широко распространенной и дешевой подложке. Добавление азота в фосфид галлия в небольших количествах приводит к уменьшению ширины запрещенной зоны, а также к изменению зонной структуры материала на прямозонную, при этом введение мышьяка позволяет корректировать значение постоянной решетки растущего материала [4,5]. Использование слоев GaPNAs в составе многопереходного солнечного элемента на кремниевой подложке, согласно численным расчетам, позволяет достичь значений кпд 44.5\% при концентрированном солнечном излучении [6]. Также активно ведутся разработки светоизлучающих приборов на основе разбавленных нитридов фосфида галлия [7]. В 2007 году группа Технологического университета Toyohashi сообщила о реализации монолитно-интегрированного светоизлучающего диода и кремниевого транзистора [8].

Легированные эпитаксиальные слои GaPNAs имеют высокую латеральную проводимость [9], что приводит к сложностям при проведении измерений электрических свойств как самих материалов, так и характеристик гомо- и гетеропереходов, сформированных на их основе. В этом случае для минимизации влияния всей поверхности материала на измерения изготавливают мезаструктуры. Травление мезаструктуры осуществляется как химическим, так и плазмохимическим способами. В последнем случае число материалов для травления практически неограниченно и возможно сформировать практически любой наклон боковой грани. Однако в некоторых случаях использование данного метода затруднено из-за образования в активном слое радиационных дефектов, приводящих, например, к снижению времени жизни носителей заряда. В случае с солнечными элементами это может привести к снижению напряжения холостого хода и кпд всего устройства в целом.

Химическое травление фосфида галлия осложнено тем, что достаточно сложно разорвать прочную кова- 
Таблица 1. Стандартные электрохимические потенциалы окислительно-восстановительных пар [12]

\begin{tabular}{l|c}
\hline \multicolumn{1}{c|}{ Реакция } & Потенциал, эВ \\
\hline $\mathrm{H}_{2} \mathrm{O}_{2}+2 \mathrm{H}^{+}+2 e^{-} \rightarrow 2 \mathrm{H}_{2} \mathrm{O}$ & 1.77 \\
$\mathrm{Ce}^{4+}+e^{-} \rightarrow \mathrm{Ce}^{3+}$ & 1.72 \\
$2 \mathrm{HClO}+2 \mathrm{H}^{+}+2 e^{-} \rightarrow \mathrm{Cl}_{2}+2 \mathrm{H}_{2} \mathrm{O}$ & 1.61 \\
{$\left[\mathrm{ClO}_{3}\right]^{-}+6 \mathrm{H}^{+}+5 e^{-} \rightarrow \mathrm{Cl}_{2}+3 \mathrm{H}_{2} \mathrm{O}$} & 1.47 \\
$\mathrm{Cl}_{2}+2 e^{-} \rightarrow 2 \mathrm{Cl}^{-}$ & 1.35 \\
$2\left[\mathrm{IO}_{3}\right]^{-}+12 \mathrm{H}^{+}+10 e^{-} \rightarrow \mathrm{I}_{2}+6 \mathrm{H}_{2} \mathrm{O}$ & 1.20
\end{tabular}

лентную связь $\mathrm{Ga}-\mathrm{P}$. Для этого используют комбинацию из сильных окислителей и комплексообразователя, способного прочно связывать продукты реакции в растворимой форме. Наличие в растворе таких окислителей, как $\mathrm{HNO}_{3}, \mathrm{H}_{2} \mathrm{SO}_{4}$ и $\mathrm{H}_{2} \mathrm{O}_{2}$, обычно применяющихся для травления $\mathrm{GaP}$, негативно сказывается на защитных свойствах фоторезиста, определяющего будущую геометрию мезаструктуры. При толщинах порядка $2-3$ мк фоторезист в таких средах деградирует - на его поверхности образуются поры, края становятся неровными. Скорость травления GaP в таких растворах крайне высока, из-за чего достаточно сложно осуществить прецизионное травление структуры.

Известно, что в водных растворах растворение GaP протекает по электрохимическому механизму [10]:

в кислой среде:

$$
\mathrm{GaP}+3 \mathrm{H}_{2} \mathrm{O}+6 p^{+} \rightarrow \mathrm{Ga}^{3+}+\mathrm{H}_{3} \mathrm{PO}_{3}+3 \mathrm{H}^{+},
$$

в щелочной среде:

$$
\mathrm{GaP}+4 \mathrm{OH}^{-}+3 p^{+} \rightarrow \mathrm{GaO}_{2}^{-}+\mathrm{P}+2 \mathrm{H}_{2} \mathrm{O} .
$$

В процессе травления происходит инжекция дырок в валентную зону полупроводника с последующим ослаблением связи $\mathrm{Ga}-\mathrm{P}$ и его растворением. Для фосфида

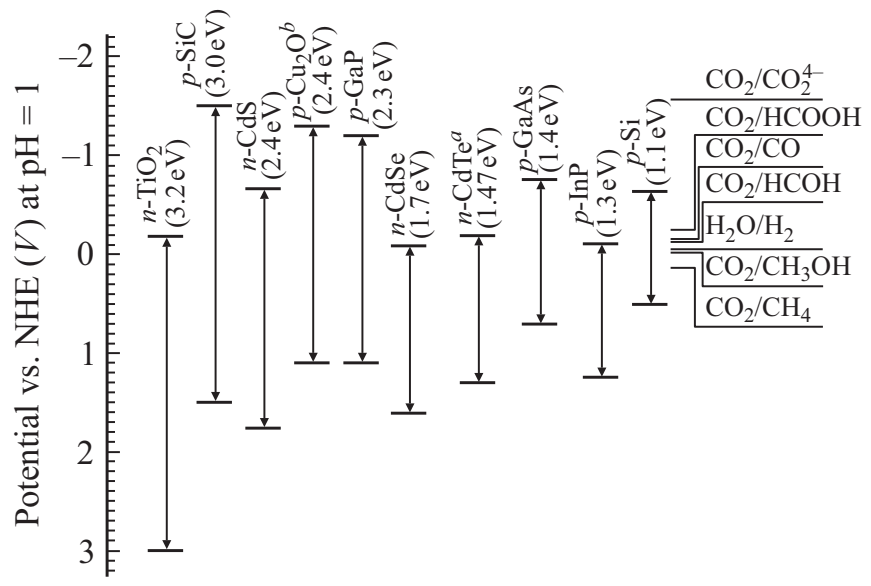

Рис. 1. Положение уровней валентной и зоны проводимости различных полупроводников при $\mathrm{pH}=1$ относительно стандартного водородного электрода [11]. галлия такой процесс может протекать в том случае, если величина формального окислительно-восстановительного потенциала редокс-пары расположена по энергии близко к уровню валентной зоны полупроводника, который составляет +1.2 эВ относительно нормального водородного электрода для раствора с $\mathrm{pH}=1$ (рис. 1). Из наиболее распространенных, таким условиям отвечают следующие окислительно-восстановительные пары (табл. 1).

Для растворения $\mathrm{GaP}$ также в растворе должен присутствовать компонент, связывающий в растворенной форме галлий и фосфор. Для фосфида галлия таким агентом может выступать ион $\mathrm{Cl}^{-}$, значение пары $\mathrm{Cl}_{2} / \mathrm{Cl}^{-}$которого согласно табл. 1 равно 1.35 эВ. Если в раствор с ионами хлора добавить окислительно-восстановительную пару со значением потенциала выше $1.35 \ni \mathrm{B}$, например перекись водорода $\left(\mathrm{H}_{2} \mathrm{O}_{2} / \mathrm{H}_{2} \mathrm{O}\right)$, то будет наблюдаться реакция выделения газообразного хлора, так как способность к окислению у $\mathrm{Cl}_{2}$ меньше (из-за меньшего значения электрохимического потенциала). Травление $\mathrm{GaP}$ в такой системе возможно, однако концентрация окислителя со временем будет снижаться из-за окисления $\mathrm{Cl}^{-}$до газообразного хлора. В случае с парой $\mathrm{IO}_{3}^{-} / \mathrm{I}_{2}$ ситуация противоположная. Окислительная способность пары все еще позволяет осуществлять травление $\mathrm{GaP}$, однако ее уже недостаточно для окисления $\mathrm{Cl}^{-}$до газообразного хлора.

\section{2. Экспериментальная часть}

Для разработки технологии прецизионного травления использовалась подложка $n-\mathrm{GaP}(100)$ с нанесенным на ее поверхность фоторезистом марки AZ5214E толщиной 2 мкм. Методом лазерной фотолитографии на поверхности $\mathrm{GaP}$ были сформированы продольные полоски из фоторезиста, расстояние между которыми составляло 20 мкм. В качестве исследуемых травителей были использованы следующие водные растворы (табл. 2).

Каждый травитель после приготовления выдерживался при комнатной температуре в течение 30 мин. В отдельных случаях при травлении осуществлялось перемешивание раствора с помощью магнитной мешалки LLG-uniSTIRRER-1 с частотой 800 об/мин. После травления $\mathrm{GaP}$ с его поверхности удалялся фоторезист в органическом травителе, после чего проводилось измерение глубины стравленного слоя с помощью профилометра AMBIOS-1 и сканирующего электронного

Таблица 2. Составы травителей, используемых в работе

\begin{tabular}{c|l}
\hline $\begin{array}{c}\text { № } \\
\text { травителя }\end{array}$ & \multicolumn{1}{|c}{ Состав } \\
\hline 1 & $\mathrm{H}_{2} \mathrm{SO}_{4}: \mathrm{H}_{2} \mathrm{O}_{2}: \mathrm{H}_{2} \mathrm{O}=3: 1: 1$ об. частей \\
2 & $\mathrm{HNO}_{3}: \mathrm{HCl}: \mathrm{CH}_{3} \mathrm{COOH}=1: 1: 1$ об. частей \\
3 & $\mathrm{KIO}_{3}: \mathrm{HCl}: \mathrm{H}_{2} \mathrm{O}=1: 1: 20$ об. частей $\left(0.2 \mathrm{M} \mathrm{KIO}{ }_{3}\right)$
\end{tabular}




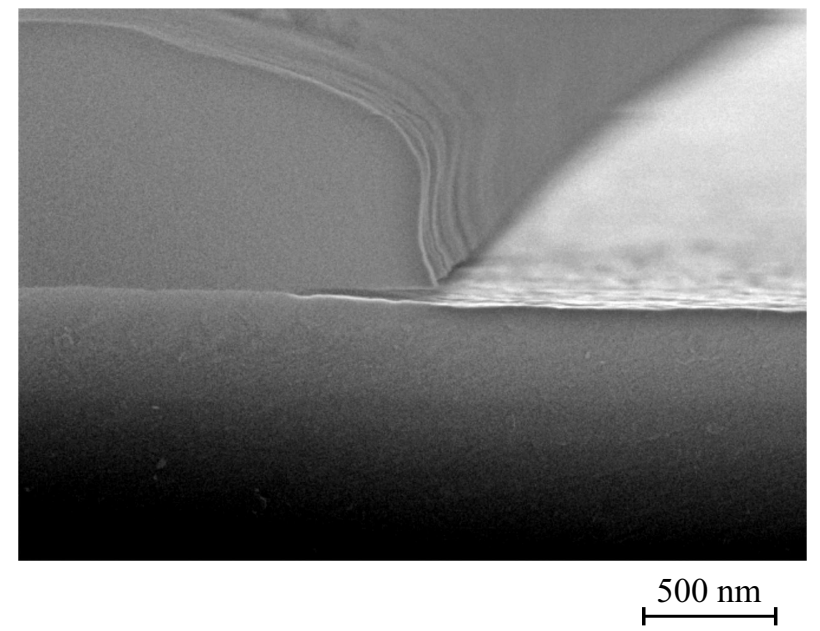

Рис. 2. СЭМ-изображение поперечного скола образца GaP после обработки в травителе № 1.

микроскопа Zeiss SUPRA 25. Вольт-амперные характеристики солнечных элементов измерялись при помощи Keitley 2400 как в темноте, так и при их освещении солнечным спектром AM1.5G при помощи имитатора солнечного освещения Abet SunLight. Спектры внешней квантовой эффективности измеряли на автоматизированной установке на основе монохроматора М266.

Травитель № 1

Концентрированная серная кислота при контакте с перекисью водорода образует пероксомоносерную кислоту (кислоту Каро). В данной системе возникает следующая окислительно-восстановительная реакция:

$$
\left[\mathrm{HSO}_{5}\right]^{-}+2 \mathrm{H}^{+}+2 e^{-}=\left[\mathrm{HSO}_{4}\right]^{-}+\mathrm{H}_{2} \mathrm{O} .
$$

Стандартный электрохимический потенциал такой системы равен 1.81 В [13], что достаточно для осуществления процесса травления $\mathrm{GaP}$. Высвобождающийся в раствор галлий связывается сульфат ионом в растворимое соединение.

При температуре раствора $25^{\circ} \mathrm{C}$ скорость травления $\mathrm{GaP}$ (без перемешивания) составила 6 нм/мин. При этом за 5 мин нахождения образца в травителе поверхность фоторезиста визуально не изменилась. Однако на СЭМ-изображениях замечен глубокий потрав в области под фоторезистом (рис. 2).

При повышении температуры раствора до $50^{\circ} \mathrm{C}$ скорость травления возросла до 60 нм/мин, однако за 5 мин, что образец находился в растворе, часть фоторезиста отслоилась от его поверхности. Через 10 мин весь фоторезист растворился в травителе. Таким образом, серно-перекисный травитель из-за растворения фоторезиста не подходит для целей прецизионного травления слоев $\mathrm{GaP}(\mathrm{NAs})$.

Травитель № 2

В данном растворе взаимодействие азотной и соляной кислот приводит к формированию окислительно-вос- становительной пары

$$
\mathrm{NO}^{+}+e^{-}=\mathrm{NO}
$$

с величной стандарного электрохимического потенциала 1.46 В. Уксусная кислота в данном травителе служит для замедления скорости реакции растворения.

Сразу же после приготовления травителя раствор пожелтел из-за начавшегося выделяться газообразного хлора. По истечении 30 мин травитель приобрел насыщенный оранжевый цвет. Скорость травления фосфида галлия в данном растворе оказалась слишком большой и составила 1000 нм/мин, что является неприемлемым для прецизионных исследований. Более того, при контакте травителя с образцом более 5 мин, так же как и в предыдущем случае, происходило растворение фоторезиста.

Травитель № 3

Для иодата калия в кислой среде характерна следующая окислительно-восстановительная реакция:

$$
2\left[\mathrm{IO}_{3}\right]^{-}+12 \mathrm{H}^{+}+10 e^{-} \rightarrow \mathrm{I}_{2}+6 \mathrm{H}_{2} \mathrm{O}
$$

с величиной стандартного электрохимического потенциала 1.2 В. При контакте с соляной кислотой окисляющей способности иодат иона недостаточно для образования газообразного хлора, зато ее достаточно для запуска процесса растворения GaP. Недостатком данного травителя является то, что в результате его работы выделяется элементарный иод, который имеет крайне низкую растворимость в воде и накапливается в зоне протекания реакции. В этом случае в области, непосредственно прилегающей к маске фоторезиста, наблюдается область с большей глубиной травления, чем на остальной поверхности полупроводника. Для снижения данного эффекта применяется активное перемешивание раствора во время травления и используется большое количество растворителя.

Для приведенного в табл. 2 состава скорость травления фосфида галлия в травителе № 3 при комнатной температуре и перемешивании составила 70 нм/мин. При

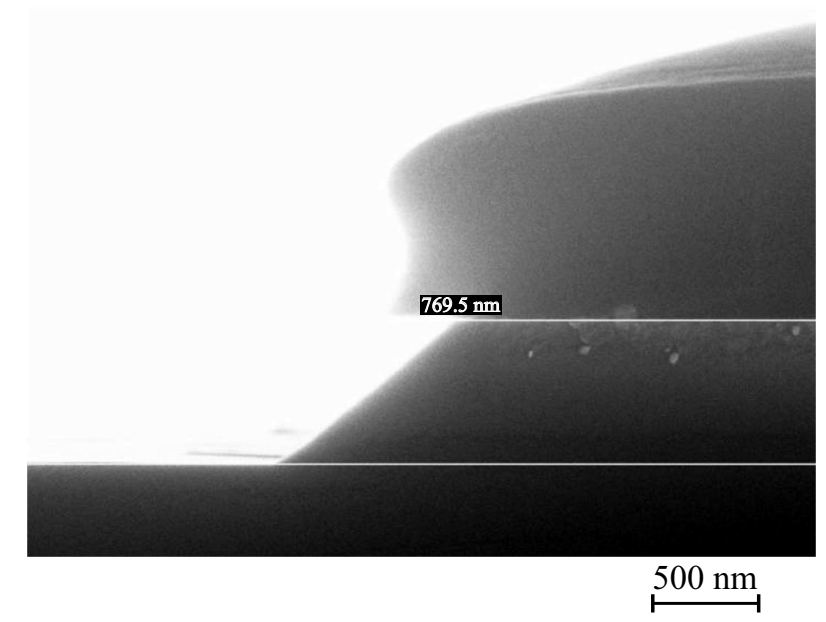

Рис. 3. СЭМ-изображение поперечного скола $\mathrm{GaP}$ после обработки в травителе № 3. 

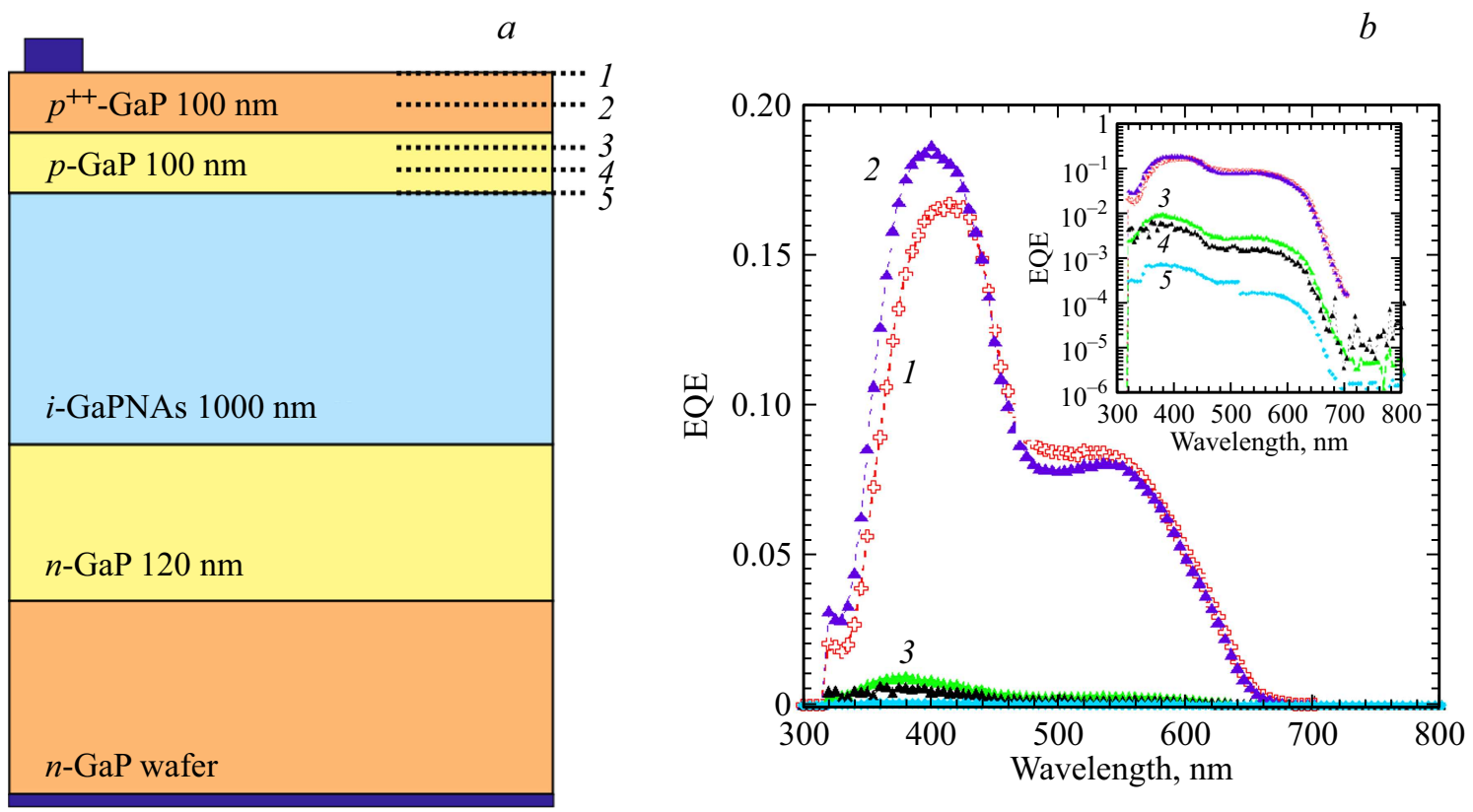

Рис. 4. Схематическое изображение $(a)$ и спектр внешней квантовой эффективности $(b)$ солнечного элемента, для которого было осуществлено послойное травление. Пунктирными линиями показано: 1 - исходная структура, 2 - удалено 50 нм, 3 - удалено 135 нм, 4 - удалено 165 нм, 5 - удалено 200 нм.

этом наблюдается селективность травления по отношению к кристаллографическим граням образца (рис. 3).

Фоторезист показал устойчивость в данном травителе при временах обработки 15 мин и более, что достаточно для травления слоев глубиной 1000 нм.

Таким образом, для прецизионного травления структур, содержащих в своем составе слои $\mathrm{GaP}(\mathrm{NAs})$, был выбран травитель № 3 .

\section{3. Практическое применение}

\section{1. Исследование спектров внешней квантовой эффективности солнечных элементов на основе GaPNAs}

На рис. $4, b$ (кривая 1) показан график спектра внешней квантовой эффективности солнечного элемента на основе GaPNAs, схематическое изображение которого приведено на рис. 4, $a$. На графике имеется два отчетливых пика. При этом сложно определенно сказать какой из слоев ( $\mathrm{GaP}$ или GaPNAs) участвует в процессе генерации фототока и оказывает ли интерференция влияние на форму кривой.

После химического травления 50 нм высоколегированного слоя GaP в травителе №3 (с перемешиванием раствора) форма графика спектра квантовой эффективности не изменилась (кривая 2), однако расширилась его коротковолновая часть и возросла интенсивность. Дело в том, что верхний слой $\mathrm{GaP}$ поглощает коротковолновую часть спектра солнечного излучения и его утонение приводит к тому, что большее количество фотонов достигает слоя GaPNAs и, как следствие, приводит к увеличению фототока.

Дальнейшее стравливание $\mathrm{GaP}$ до эмиттерного слоя (кривая 3) приводит к тому, что интенсивность спектра внешней квантовой эффективности начинает резко снижаться, однако его форма не меняется (см. вставку на рис. $4, b)$. При полном удалении данного слоя резко снижается латеральная проводимость и, как следствие, собираемость фотогенерированных носителей заряда. Дальнейшее утонение уже эмиттерного слоя приводит к снижению потенциала на гетерогранице, в результате чего меньшее число носителей заряда достигает электрических контактов солнечного элемента. При полном удалении эмиттерного слоя $\mathrm{GaP}$ форма спектра квантовой эффективности по-прежнему характеризуется двумя пиками, однако их интенсивности крайне малы (кривая 5).

Таким образом, с помощью прецизионного химического травления было показано, что форма спектра внешней квантовой эффективности связана только с особенностями электронного строения слоя GaPNAs [9].

\section{2. Формирование меза-структуры для измерения характеристик солнечного элемента на основе GaPNAs}

При исследовании характеристик солнечных элементов необходимо знать площадь поверхности, с которой собирается весь фототок. В случае высокой латеральной проводимости приконтактного слоя площадь, с которой собирается фототок, может значительно превышать ту, 
$a$

\begin{tabular}{|l|}
\hline \multicolumn{2}{c}{$a$} \\
\hline$p^{++}$-GaP $80 \mathrm{~nm}$ \\
\hline$p$-GaPN $100 \mathrm{~nm}$ \\
\hline i-GaPNAs $300 \mathrm{~nm}$ \\
\hline$n$-GaPNAs $300 \mathrm{~nm}$ \\
\hline$n$-GaP $100 \mathrm{~nm}$ \\
\hline$\ldots$ \\
$n$-GaP wafer \\
\hline
\end{tabular}

$b$

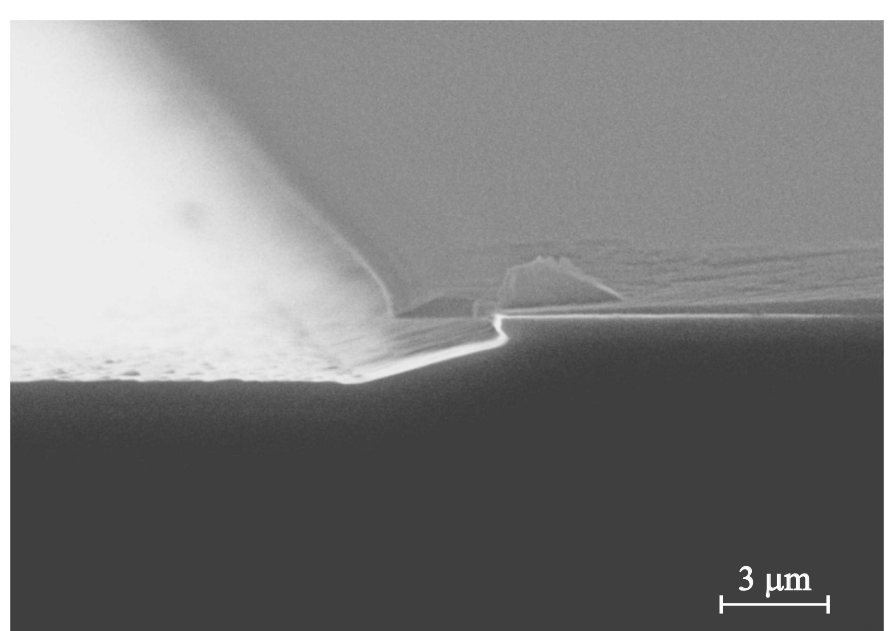

Рис. 5. Схематическое изображение однопереходного солнечного элемента на основе GaPNAs $(a)$ и его СЭМ-изображение после травления $(b)$.

что ограничена контактной сеткой. В этом случае измеренное значение величины плотности тока короткого замыкания будет превышать реальную, что приведет к неверной оценке кпд солнечного элемента. То же самое касается и емкостных измерений, когда ошибка в оценке площади контактной площадки приводит к неверному расчету концентрации носителей в полупроводнике. Формирование мезаструктуры позволяет ограничить и зафиксировать размеры рабочей области полупроводникового прибора.

Для формирования мезы был взят однопереходный CЭ на основе GaPNAs c шириной запрещенной зоны 1.7 эВ, выращенный на $\mathrm{GaP}$-подложке (рис. 5,a). Травление мезы осуществлялось в травителе № 3 с перемешиванием раствора при комнатной температуре. На поверхности образца при помощи фотолитографии

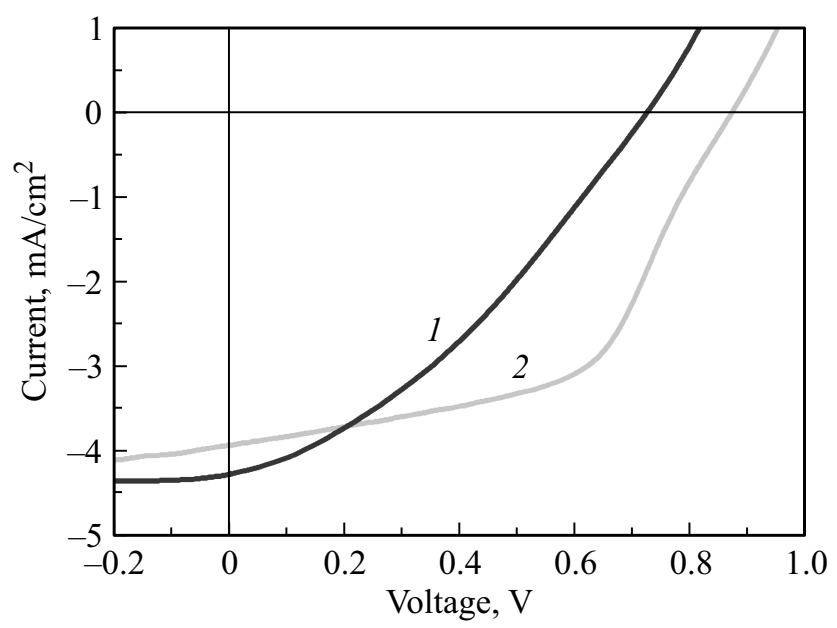

Рис. 6. Вольт-амперная характеристика однопереходного солнечного элемента до формирования мезы (1) и после (2). была сформирована маска из фоторезиста, задающая форму будущей мезы. Как видно из рис. $5, b$, травление слоев GaP и GaPNAs идет с различной скоростью, вследствие чего формируется различный наклон стенки мезы. Данное обстоятельство необходимо учитывать при выборе метода формирования пассивационных покрытий на последующих этапах.

На рис. 6 показаны вольт-амперные характеристики (BAX) солнечного элемента, измеренные до формирования мезы и после. На графике видно, что после травления немного уменьшился ток короткого замыкания, что, скорее всего, связано с более точной оценкой площади рабочей поверхности солнечного элемента. Из рис. 6 также видно, что после формирования мезы существенно возросло значение напряжения холостого хода и фактора заполнения ВАХ, что связано со снижением влияния шунтирования за счет утечек на периферийной поверхности солнечного элемента.

\section{3. Исследование характеристик отдельных субэлементов в двухпереходном GaPNAs/Si-солнечном элементе}

Важной задачей при изготовлении многопереходных СЭ является исследование характеристик отдельных переходов, составляющих СЭ. Если для измерения спектров внешней квантовой эффективности достаточно с помощью постоянной внешней подсветки открыть один из переходов и проводить исследование второго, то для измерений вольт-амперных и емкостных характеристик необходимо иметь электрические контакты к каждому из переходов.

Для исследования был взят двухпереходный солнечный элемент с верхним переходом на основе GaPNAs с шириной запрещенной зоны 1.9 эВ и нижним - на 
$a$

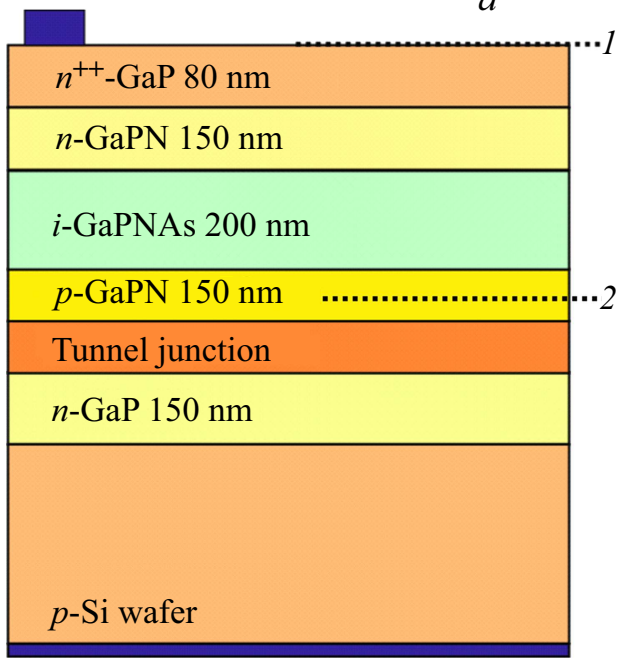

$b$

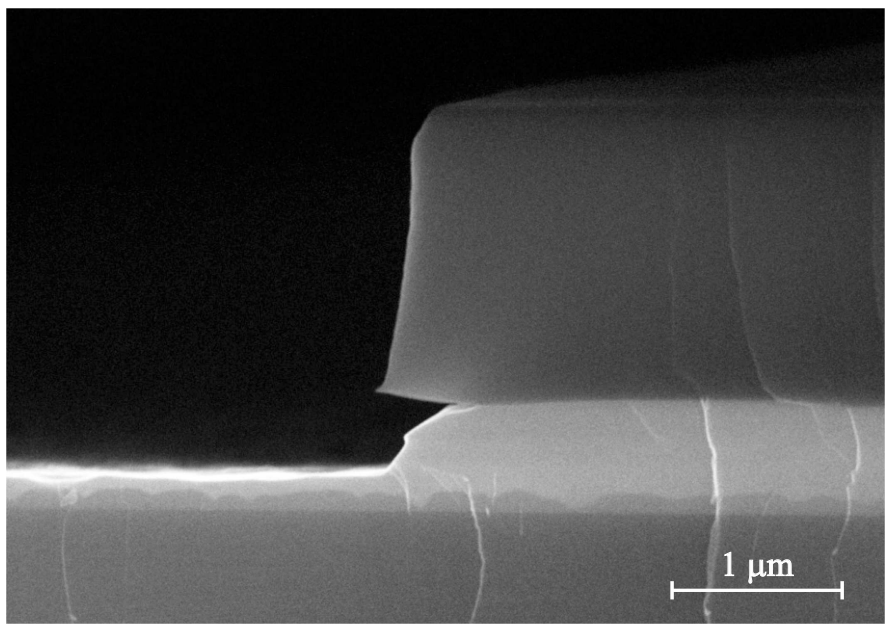

Рис. 7. Схематическое изображение двухпереходного солнечного элемента на основе GaPNAs $(a)$ и его СЭМ-изображение после травления $(b)$.

основе кремния (рис. 7,a). С помощью метода фотолитографии была сформирована маска из фоторезиста, ограничивающая область травления. Так как состав слоев образца довольно сильно менялся по мере травления, то менялась и скорость травления для каждого из слоев. Чтобы точно определить время, необходимое для стравливания нужной толщины, были проведены вспомогательные эксперименты по травлению в травителе № 3 этой же структуры с различным временем травления и с последующим удалением фоторезиста и измерением глубины стравленной области. На рис. 7, $b$ представлено СЭМ-изображение двухпереходного СЭ после удаления 530 нм. Затем на стравленной области с помощью методов фотолитографии и термического напыления были сформированы омические контакты и

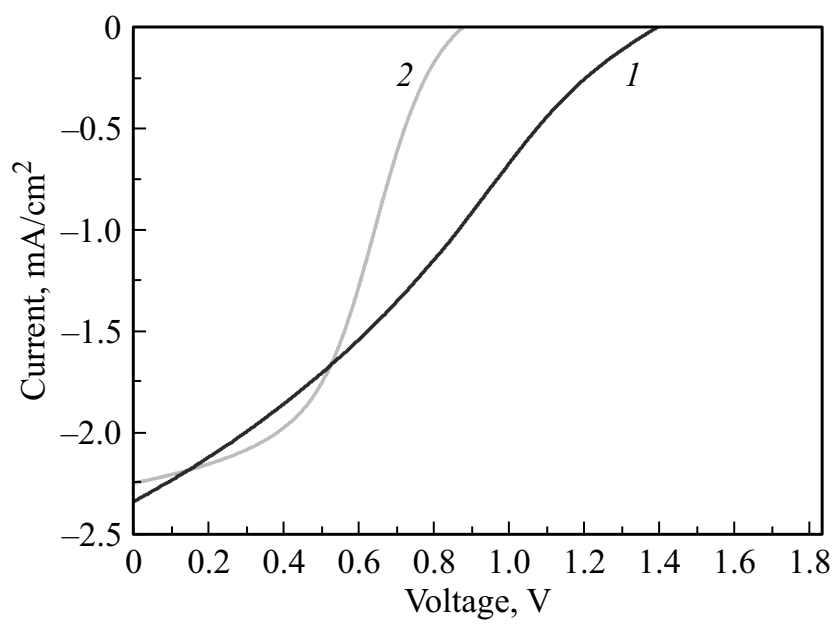

Рис. 8. Вольт-амперная характеристика двухпереходного солнечного элемента (1) и его верхнего перехода (2). измерены ВАХ как двухпереходного СЭ, так и отдельно верхнего перехода (рис. 8).

Из рис. 8 видно, что напряжение холостого хода для верхнего перехода составляет 0.9 В. Соответственно кремниевый переход обеспечивает оставшиеся $0.5 \mathrm{~B}$. Ток короткого замыкания верхнего перехода составляет $2.2 \mathrm{MA} / \mathrm{cm}^{2}$ и близок к значению тока двухпереходного СЭ, что прямо указывает на то, что он является ограничивающим по току в двухпереходной системе. С другой стороны, видно, что фактор заполнения для двухпереходного СЭ существенно ниже по сравнению с однопереходным. Данный факт однозначно свидетельствует об ограничении транспорта носителей заряда туннельным переходом между субэлементами на основе GaPNAs и $\mathrm{Si}$, конструкция которого требует оптимизации.

\section{4. Заключение}

Таким образом, было показано, что травитель на основе иодада калия и соляной кислоты подходит для задач прецизионного травления образцов, содержащих слои GaPNAs. Скорость травления $n$-GaP для состава, указанного в табл. 2, при комнатной температуре и при перемешивании раствора со скоростью 800 об/мин составляет $70 \mathrm{Hм} /$ мин. Наличие в составе полупроводника азота (до 4\%) и мышьяка не оказывает существенного влияния на работу травителя, однако требует проведения дополнительных калибровочных экспериментов по уточнению скорости травления в каждом конкретном случае.

Работа выполнена при поддержке гранта Российского научного фонда (проект № 17-19-01482). 


\section{Список литературы}

[1] J.F. Geisz, D.J. Friedman, S. Kurtz. Proc. 29th IEEE Photovoltaics Specialists Conf. (New Orleans, Louisiana, 864-7, 2002).

[2] S. Essig, M.A. Steiner, Ch. Allebé, J.F. Geisz, B. PavietSalomon, S. Ward, A. Descoeudres, V. LaSalvia, L. Barraud, N. Badel, A. Faes, J. Levrat, M. Despeisse, Ch. Ballif, P. Stradins, D.L. Young. IEEE J. Photovolt., 6, 1012 (2016).

[3] S. Ilahi, S. Almosni, F. Chouchane, M. Perrin, K. Zelazna, N. Yacoubi, R. Kudrawiec, P. Răle, L. Lombez, J.-F. Guillemoles, O. Durand, C. Cornet. Solar Energy Mater. Solar Cells, 141, 291 (2015).

[4] W. Shan, W. Walukiewicz, K.M. Yu, J. Wu, J.W. Ager, E.E. Haller, H.P. Xin, C.W. Tu. Appl. Phys. Lett., 76, 3251 (2000).

[5] I.A. Buyanowa, G. Pozina, J.P. Bergman, W.M. Chen, H.P. Xin, C.W. Tu. Appl. Phys. Lett., 52, 81 (2002).

[6] Д.А. Кудряшов, А.С. Гудовских, Е.В. Никитина, А.Ю. Егоров. ФТП, 48 (3), 396 (2014).

[7] А.В. Бабичев, В.Ю. Бутко, М.С. Соболев, Е.В. Никитина, Н.В. Крыжановская, А.Ю. Егоров. ФТП, 46, 815 (2012).

[8] S.Y. Moon, H. Yonezu, Y. Furukawa, Y. Morisaki, S. Yamada, A. Wakahara. Phys. Status Solidi, A, 204 (6), 2082 (2007).

[9] А.И. Баранов, А.С. Гудовских, Е.В. Никитина, А.Ю. Егоров. Письма ЖТФ, 39 (24), 88 (2013).

[10] R. Memming, G. Schwandt. Electrochimica Acta, 13, 1299 (1968).

[11] B. Kumar, M. Llorente, J. Froehlich, T. Dang, A. Sathrum, C.P. Kubiak. Annu. Rev. Phys. Chem., 63, 541 (2012).

[12] CRC Handbook of Chemistry and Physics, 84th edn, ed. by David R. Lide (CRC Press LLC, Boca Raton, 2003).

[13] J. Monhemius. Mineral Processing and Extractive Metallurgy Review, 8 (1-4), 35 (1992).

Редактор Г.А. Оганесян

\section{Precise chemical etching of GaP(NAs) epitaxial layer for monolithic optoelectronic devices manufacturing}

D.A. Kudryashov ${ }^{1}$, A.S. Gudovskikh ${ }^{1,2}$, A.I. Baranov ${ }^{1}$

${ }^{1}$ St. Petersburg National Research Academic University, Russian Academy of Sciences, 194021 St. Petersburg, Russia,

2 St. Petersburg Electrotechnical University „LETl“, 197376 St. Petersburg, Russia

Abstract The results of a study of the applicability of various etchants for the purpose of precision wet etching of structures of monolithic optoelectronic devices containing GaPNAs layers are presented. It has been shown that an etchant based on potassium iodide and hydrochloric acid is best suited for this purpose. The presence of nitrogen (up to $4 \%$ ) and arsenic in the semiconductor compound does not have a significant effect on the work of the etchant, but requires additional calibration experiments to refine the etching rate in each particular case. The paper presents examples of the practical application of precision etching to measure the characteristics of GaPNAs based solar cells. 